\title{
The Impact of Concept Mapping on EFL Learners' Critical Thinking Ability
}

\author{
Ebrahim Khodadady (Corresponding author) \\ Department of English Language and Literature, Ferdowsi University of Mashhad \\ Mashhad, 91779-48883, Iran
}

Tel: 98-91-5157-0733 Email: ekhodadady@ferdowsi.um.ac.ir

Afsaneh Ghanizadeh

Department of English Language, Islamic Azad University, Mashhad Branch, Iran

Tel: 98-91-5304-8141Ｅ-mail: ghanizadehafsaneh@yahoo.com

$\begin{array}{lcc}\text { Received: May 16, } 2011 & \text { Accepted: September 18, } 2011 & \text { Published: December 1, } 2011 \\ \text { doi:10.5539/elt.v4n4p49 } & \text { URL: http://dx.doi.org/10.5539/elt.v4n4p49 }\end{array}$

\begin{abstract}
The present study investigated the influence of concept mapping as a post-reading strategy on EFL learners' critical thinking ability. The study utilized a pretest - posttest control and experimental group design. To do so, thirty six EFL learners at upper intermediate and advanced levels were randomly assigned to experimental $(n=18)$ and control $(n=18)$ groups. The results of pretest indicated that the participants of the two groups were homogenous with regard to their proficiency level and critical thinking ability. The experimental group was instructed to construct concept maps after reading each text and formulated the required post-reading activities on the basis of the constructed maps. Critical thinking skill was assessed via the "Watson-Glaser Critical Thinking Appraisal" (CTA). The results of posttest indicated that concept mapping has a positive and significant influence on learners' critical thinking ability. The discussion and conclusions of the research are further presented with reference to the finding.
\end{abstract}

Keywords: Concept mapping, Critical thinking, EFL learners, Post-reading strategy

\section{Introduction}

Concept maps are graphical representations of knowledge. They allow us to understand the relationship between ideas by creating a visual map of the connections. They are composed of concepts, enclosed in circles or boxes, and connecting lines indicating the relationships between concepts or propositions (Cañas, 2003). In constructing concept maps, it is important to note that concept words or phrases are referred to as nodes and are placed in boxes or circles. The connecting structures between the nodes are called links and are represented by labeled lines or arrows. A proposition, then, is defined as two concepts connected by a labeled link. The concepts are usually rank ordered from the most general, most inclusive concept to the most specific, least general concept. A standard procedure for concept map construction, according to Cañas, Hill, Carff and Suri, (2003), involves defining the topic or focus question, identifying and listing the most important or general concepts that are associated with that topic, ordering the concepts from top to bottom, and adding and labeling linking phrases. Figure 1 portraits a concept map representing the key ideas and principles in constructing concept maps (See Appendix A).

Interest in concept mapping stems from its relationship to memory and learning theory. Psychological foundation of concept maps derives from Ausubel's meaningful learning. This theory is based on the assumption that learning takes place in the human organization through a meaningful process of relating and anchoring new events or items to already existing cognitive concepts or propositions. Novak (1998) contended that concept maps adequately fulfill the fundamental requirements of meaningful learning. For meaningful learning to occur, it must meet three requirements: 1) relevant prior knowledge 2) meaningful material 3) learner's conscious and deliberate choice to learn meaningfully (Novak \& Gowin, 1984). Novak (1998) believed that in any educational setting, the teacher can encourage this choice by using tools such as concept maps. When these requirements are successfully fulfilled, the result would be meaningful learning and ultimately creative production.

The epistemology- knowledge source and creation- of concept maps builds on the theory of learning of concept maps. It is based on human constructivism. According to this view, meaningful learning occurs when humans 
actively integrate thinking, feeling, and acting to construct meaning and knowledge (Novak, 1998). The fact that the nature and process of meaningful learning underlie both human learning and knowledge creation is manifested in Novak and Gowin's (1984) contention stating that "psychology of meaningful learning gives rise to the epistemological process of knowledge creation" (p. 92). Figure 2 illustrates such an association (Appendix B).

Due to the organizing nature of concept maps, they have been extensively used in educational settings as learning, assessment, communication, and brainstorming tools. Numerous educational applications of concept mapping can be summarized as:

1) a scaffold of understanding, 2) a tool for the consolidation of educational experiences, 3) a tool for
improvement of affective conditions for learning, 4) an aid or alternative to traditional writing
assignments, 5) a tool to teach critical thinking, 6) a mediating representation for supporting
interaction among learners, and 7) an aid to the process of learning by teaching. (Cañas, 2003, p.7)

Although, the literature on concept mapping has been primarily concerned with the application of concept maps to science contexts, in recent years educators have begun to report on the benefits and effectiveness of concept mapping strategies in L2 settings and for a variety of purposes. In the domain of L2 reading comprehension, for instance, Carrel, Pharis and Liberto (1989) argued the effectiveness of text mapping techniques in enhancing second language reading as a proper alternative to traditional pre-reading and post-reading activities. In this application, they used mapping as a tool not only to introduce the key vocabulary from the passage, but also to provide the teacher with an assessment of the students' prior knowledge on the topic. In a recent study, Ghanizadeh (2007a) reported the positive influence of concept map construction on EFL learners' reading comprehension, as well as on the attitudes toward EFL reading comprehension. The study revealed that as the result of integrating concept mapping technique during reading or post-reading phase, EFL students learned to show the interrelationships existing in the passage by identifying the main ideas and putting them in circles or boxes, and by establishing the connections between ideas and forming propositions.

Some researchers argue that the benefit of concept mapping might extend beyond the instructional gains to include higher order cognitive capabilities such as self-regulation and self-efficacy. Chalurt and Debaker's (2004) findings, for example, demonstrated a statistically significant influence of concept mapping on achievement, self-regulation, and self-efficacy in students of English as a second language. Similarly, Talebinezhad and Negari (2007) investigated the positive influence of concept mapping as a learning strategy on EFL learners' self-regulation in writing classes. The findings confirmed the hypothesis that concept mapping promotes students' self-regulation. Although, the above-mentioned studies demonstrate the impact of concept mapping on higher order facets such as motivation, self-efficacy beliefs, self-regulation abilities, and attitudes, there seems a dearth of research on the role of concept mapping in fostering learners' thinking and reasoning skills, specifically critical thinking abilities in L2 settings. Indeed, concept maps have been extensively described as "metacognitive tools" (Mintzes, Wandersee \& Novak, 1997, p. 411) that enable learners to think reflectively about what they are learning through the visual representation of concept relationships and associations. The present study set out to empirically examine this gap in an EFL context.

\section{A Brief Overview on Critical Thinking}

There are a multitude of definitions for what constitutes critical thinking. Historically, Dewey (1933) described critical thinking from a philosophical perspective by viewing education as a systematic approach to provide conditions to cultivate habits or training of the mind. He believed aspects of critical thinking included inquiry, discrimination, testing beliefs and considering alternatives. Ivie (2001) defined critical thinking in terms of reflective practice enabling learners to "establish clear and logical connections between beginning premises, relevant facts, and warranted conclusions" (Ivie, 2001, p.10). More recently, critical thinking has been viewed as more than cognitive skills. Scriven and Paul (2004) defined critical thinking as, "the mode of thinking in which the thinker improves the quality of his or her thinking by skillfully taking charge of the structures inherent in thinking and imposing intellectual standards upon them". This definition incorporates the metacognitive skill of evaluating one's own thinking processes. Another definition focuses on critical thinking as self-directed and disciplined thinking "which exemplifies the perfections of thinking, appropriate to a particular mode or domain of thought" (Paul, 1990, p. 49). Critical thinking is defined by the American Philosophical Association Project as purposeful, self-regulatory judgment which results in interpretation, analysis, evaluation and inference and is founded on the conceptual criteria upon which a judgment is based (Facione \& Facione, 1996).

Despite the controversy over a unified definition for what constitutes critical thinking, there is a general consensus that critical thinking can be influential in almost every discipline and occupation, and it has also been found to be consistently required to meet all academic objectives (Facione \& Facione, 2006). In an educational setting, it is 
widely accepted that learning to think is one of the most important goals of formal schooling. Dewey (1933), for example, stated that the central purpose of education is learning to think. As part of that education, learners need to develop and learn to apply critical thinking skills to their academic studies effectively (Keeley, Holland, \& Watson, 2005), to the complex problems that they will face in their professions (Yeh, 2004), and to the critical choices they will be forced to make as a result of the information explosion and other rapid technological changes (Oliver \& Utermohlen, 1995). In an EFL context, it seems that attention to critical thinking deserves the additional considerations due to the position of problem-solving, attitudes, self-regulation, and meta-cognitive abilities in EFL classes.

In a similar vein, more recently, ways in which critical thinking might be interpreted and taught have become highly debated questions for EFL learning scholars and practitioners (Thompson, 2002). A shift has occurred from viewing learning primarily as rote training to conceptualizing learning as a constantly evolving process of discovering, questioning, and reformulating hypotheses (Pennycook, 1994). Critical thinking skills have also gained attention in research related to student attitudes and achievement and a diverse body of educational research reported the importance of promoting higher-order thinking skills and the positive influence of critical thinking on learners' achievement in EFL contexts (e.g., Davidson \& Dunham, 1997; MacBride \& Bonnette, 1995). The argument is that higher-order thinking skills enhance higher order learning skills which in turn facilitate attaining higher levels of language proficiency (Renner, 1996).

\section{Justification of the Study}

Current approaches to undertaking reading comprehension ability are enjoying a shift from traditional and computer-like perspectives of reading to more interactive and constructivist approaches. The constructivist theory to reading contends that meaning construction is accomplished in three ways: by organizing the context according to the text structure, by selecting context on the basis of saliency and importance of ideas, and by connecting context through inference making and elaborations (Spivey \& Mellon, 1989). The first aspect of constructivismorganization- includes the knowledge organization, such as schemata and frames, as well as organization of text structure, discourse comprehension, and mental representation. Via the second aspect of constructivism, selection, readers come to adopt an important principle based on the prominence expressed in the text. In the case of expository texts, hierarchical structures with various levels of importance in the propositional content determine the selection process. The reader formulates the gist of the most significant information present in the context by eliminating some unimportant or irrelevant information in the text, by integrating text elements into complex units, and by forming a whole sequence of propositions. Selection process is also determined by contextual factors, such as readers' goals and attitudes, in addition to textual elements.

Connection, the third aspect of constructivism, is realized either at global or local levels. Global coherence, the overall unity of the text along with the mental representation, is mainly due to the two aforementioned aspects of constructivism: organization and selection, and to some extent to what the discourse is about, i. e. theme or topic. The local-level connections consist of linear links such as logical connectives, linguistic cohesion, topic-comment structure, given-new placement of information and referential overlap. Of course, here it must be noted that meaning construction during reading entails not only reading in-lines but also reading between-lines by making their own connections and inference making.

It appears that constructivist approach to reading entails the involvement of abilities such as inference-making, discourse comprehension and reading between lines, all of which may contribute to the development of critical thinking. This is in line with the definition of critical thinking adapted in the present study and formulated by Watson and Glaser (2002). They maintained that critical thinking is associated with the following abilities:

inferences drawn from factual statements, recognition of assumptions in a series of statements, interpreting whether conclusions are warranted or not, determine if conclusions follow from information in given statements, evaluating arguments as being strong and relevant or weak and irrelevant. (pp. 21-230)

Hence, it seems reasonable to presume that organizational tools such as concept maps, drawn heavily from constructivism, can enhance critical thinking abilities.

Another justification of conducting the present study originates from the general consensus among the scholars in the field of education that deem developing CT skills of learners an indispensable part of the agenda of education, required for full and constructive participation in academic, individual and social lives of students (Scriven \& Paul, 2004). Brookfield (1989) pointed out that schools should make any endeavor to "awaken, prompt, nurture and encourage the process of thinking critically and reflectively" (p. 11). Similarly, Meyers (1986) argued that teachers can foster CT through the activities they assign, the tasks they set, and the feedback they provide. 
In a similar vein, the tenets pertained to $\mathrm{CT}$ in attaining academic objectives have become a paramount inquiry for EFL and ESL researchers and practitioners. What has emerged from these studies is compatible with Davidson and Dunham's (1996) argument that CT skills are teachable and can be reinforced via different techniques and activities implemented in the classroom setting. For instance, Dantas-Whitney (2002) indicated that use of reflective audiotaped journals enhanced ESL university students' CT. In a similar vein, Faravani's (2005) study demonstrated that portfolios foster EFL learners' CT ability. More recently, Iiaw (2007) revealed that the implementation of content-based approach promotes EFL learner's CT skills.

To examine the effectiveness of concept mapping as a technique an EFL teacher may have at his/her disposal to enhance EFL learners' CT abilities, the present study addresses the following question:

Does concept mapping as a post-reading strategy have any significant impact on EFL learners' critical thinking ability?

\section{Method}

\subsection{Participants}

The participants of the present study consisted of thirty six advanced and upper-intermediate EFL learners (thirty-one females and five males) studying at Marefat, an English institute in Mashhad, a city in north-eastern Iran. They were all CAE candidates who had already passed FCE courses successfully. They were randomly assigned to control and experimental groups. To ensure that learners were at the expected proficiency level and to have a more homogenous group, the disclosed Test of English as a Foreign Language (TOEFL) administered by Educational Testing Service (ETS) in January 2004 along with the "Watson-Glaser Critical Thinking Appraisal" (2002) were administered as pretests.

\subsection{Instruments}

As stated earlier, to determine the level of the learners' English proficiency, a TOEFL test (ETS, January 2004) was utilized. The test comprises 140 items in three sections: section 1 (listening comprehension), section 2 (structure and written expression), and section 3 (reading comprehension). Section 1 consists of 50 items and the allotted time is 30 minutes. Section 2 comprises 50 items with the time limit of 25 minutes and section 3 includes 50 items with the allotted time of 55 minutes.

To measure the participants' critical thinking ability, the "Watson-Glaser Critical Thinking Appraisal" (CTA) (Form A) was employed. The test comprises 80 items and consists of 5 subtests outlined in Table 1. It was administered to both control and experimental group twice, once as a pretest and the other as posttest. The internal consistency reliability estimate of the CTA administered as a posttest in this study was 0.81 (Alpha).

\subsection{Procedure}

The present study was conducted over 22 two-hour sessions between May and July 2010. The following five steps determined the delivery and the sequence of the study: 1) proficiency pretest with control and experimental groups, 2) critical thinking pretest with control and experimental groups, 3) two sessions of instruction on concept map construction with experimental group, 4) integration of concept mapping as a post reading strategy in experimental group, and 5) critical thinking posttest with both groups.

As stated earlier, to check the homogeneity of students, the TOEFL (ETS 2004) was administered to the students, and to ensure the homogeneity of students regarding their critical thinking ability, the CTA was utilized at the onset of the term. All the participants sat for the tests concurrently and at a single session. To reduce the possible fluctuation of order effect, the order of administration was counterbalanced, i.e. half of the participants were first given TOEFL and then CTA, while the other half were first administered CTA and TOEFL second.

Based on the results of pretest, the participants were randomly assigned to two groups of control and experimental. The two classes were conducted by the same teacher. The course book Advanced Gold (Acklam \& Burgess 2001), and the instructional materials (some reading extracts from IELTS and TOEFL reading modules) were identical for both groups. The only difference was that the students in the experimental group were engaged in concept map construction after reading each text and organized their post-reading activities such as discussion, doing exercises, and reflective practices according to their constructed maps. Conversely, the students in the control group did not develop their post-reading activities based on concept mapping technique.

The students in experimental group were initiated to concept mapping through two briefing sessions. In so doing, these steps were taken:

- Introducing concept mapping; 
- Distributing a reading passage along with the corresponding concept map;

- Reflecting on and analyzing the aforementioned passage and the parallel concept map;

- Distributing a passage and asking them to fill in the circles of the incomplete teacher-constructed concept map (Appendix C);

- Distributing a passage and asking them to construct the corresponding concept map;

- Identifying the main ideas or key concepts in the passage, and putting them in boxes or squares;

- Establishing the relationships between the identified ideas by arrows;

- Making comparisons between their own constructed map and the teacher-constructed map;

- Exchanging their constructed maps and discussing on controversies.

To create concept maps, the participants were required to extract the main ideas or concepts of the passage in the form of words or phrases, and put them in squares. The squares were then connected together by arrows based on the relationships embedded in the passage. To specify the kind of relationship, they were asked to label the arrows by linking phrases or words.

In the course of 20 -session interval between pretest and posttest, each session the participants of both groups were distributed a reading passage besides their course book reading passages. The teacher utilized the identical procedure in instructing the passage in control and experimental groups. The same assignments and post-reading activities were also considered for the subsequent class hour. The participants of the experimental group, nevertheless, were required to construct the corresponding concept map of each passage at home and arrange the required post-reading activities based on those maps. To draw maps, they were encouraged to employ the software C-map tools version 4.09 designed by Institute for human and machine cognition. The maps were, then, compared and reflected upon to identify premises, inductive and deductive reasoning, and inferences. They also facilitated discerning misunderstandings and misconceptions as well as understanding rhetorical functions such as cause-effect relationships, compare-contrast relationships, arguments, etc.

\section{Results}

\subsection{Results of the pre-test}

As stated earlier, to ensure that participants were at the same proficiency level, a TOEFL test was administered. Table 2 displays the results of pretest. As the table suggests there was no statistically significant difference between the two groups with respect to their proficiency level $(\mathrm{t}=1.533, \mathrm{p}<.05)$. (See table 2 )

To check the homogeneity of participants regarding their critical thinking ability prior to instruction, the "Watson-Glaser Critical Thinking Appraisal" (CTA) was administered to the participants of each group. Table 3 presents summary descriptive statistics of the CTA in each group. (See table 3)

Table 4 displays the results of pretest on CTA. As the table indicates there was no statistically significant difference $(\mathrm{t}=.560, \mathrm{p}<.05)$ between the two groups with respect to their CTA scores. (See table 4$)$

\subsection{Results of the post-test}

To investigate the effect of concept mapping on critical thinking ability, the CTA was administered to the participants of the two groups at the end of the term. Table 5 summarizes the descriptive results of CTA scores in control and experimental.

Table 6 presents the results of T-Test run on CTA held as a posttest. As can be seen, there is a statistically significant effect of concept mapping on the learners' critical thinking ability $(t=3.527, \mathrm{p}<.05)$.

\section{Discussion}

This study intended to investigate whether concept mapping as a post-reading strategy had any impact on EFL learners' critical thinking ability. The results indicated that concept mapping positively and significantly influenced critical thinking. In other words, the integration of concept mapping to EFL reading classes tends to foster learners' critical ability. The results confirmed the findings of Wheeler and Collins (2003) that concept mapping is effective in assisting nursing students develop critical thinking skills. Jonassen, Carr and Yueh (1998) also argued that semantic organization tools [such as concept maps], scaffolding different forms of reasoning about content, engage students in thinking critically about the content of whatever they study. The findings of the present study extend those of previous studies to EFL reading classes where upper intermediate and advanced learners are engaged in assessing arguments and statements, deducing conclusions and hypotheses, detecting inconsistencies and common mistakes in reasoning, and making inferences. 
The findings of the present study also substantiate the contention formulated earlier in this paper that adopting the constructivist theory to reading and developing critical thinking abilities may be closely associated. In other words, organizational representations such as concept maps, signifying concepts and establishing relations among concept may pave the way for the manifestation of constructivist reading- accomplished through organization, selection, and connection- as well as critical thinking abilities. This is consistent with previous research on concept mapping as an assessment tool of EFL reading comprehension (Ghanizadeh, 2007b) which investigated test-taking strategies of concept mapping via think aloud procedure. The results indicated that among the strategies associated with higher-order abilities, proposition synthesizing and inference-making were the most recurrent ones.

Various properties inherent in concept mapping may have contributed to the enhancement of learners' critical thinking ability. Extracting the main ideas or concepts of the passage and enclosing them in squares or boxes may have helped them conceptualize and organize text ideas and information into a coherent whole. The hierarchical nature of concept maps may have facilitated distinguishing major from minor ideas and essential from nonessential. By connecting the squares together based on the relationships embedded in passages, learners could have deduced the ideas not explicitly stated in the text. It could have also resulted in the deactivation of materials that do not fit into the overall discoursal context. Labeling the arrows by linking phrases or words may have enabled the learners to understand and identify the rhetorical functions such as cause-effect, compare-contrast, arguments, etc, as well as deciding upon deductively and inductively valid arguments. Furthermore, the visual property of concept maps seems to have played a facilitative role in aiding learners to make the abstract more concrete and in creating a holistic frame of the text that words alone cannot convey. This in turn could have aided the learners to locate main ideas, to distinguish between salient and subsidiary points or arguments, and to identify and conceptualize the text structure. All the above-mentioned qualities fall adequately within higher-order abilities associated with making meaning from text and reading between lines, such as inference-making, deduction, argument evaluation, and interpretation, all of which are manifestations of critical thinking ability.

Taken together, the findings of the present study confirmed Meyers' (1986) argument that teachers can foster CT through the activities they assign and the tasks they set. Davidson and Dunham (1996) also contended that CT skills could be taught as part of EFL instruction. In line with these contentions, the present paper demonstrated the influential role EFL teachers can play in scaffolding activities and procedures which nurture and foster EFL learners' CT abilities.

\section{Conclusions}

In essence, the yielded results of the present study lead to this conclusion that concept mapping fosters EFL learners' critical thinking ability in reading classes. As a result of this ability learners are to question or evaluate the validity of ideas or premises residing in the texts and to identify the lines of reasoning and arguments along with the associated fallacies. It seems plausible to expect learners transfer this ability to other skills and areas. This in turn may yield greater academic and life achievements since according to current trends of education, critical thinking skills are necessary for success in education and life. As Wright (2002) argued, the complexity of modern life necessitates developing and applying critical thinking abilities. Complicated situations cannot be solved by simple thinking; they need higher-order intellectual or cognitive abilities including complex critical kind of thinking.

In view of the significant theoretical and educational implications derived from critical thinking, this skill has been found to be associated with other higher-order cognitive and meta-cognitive abilities. For instance, Phan (2010) contended that critical thinking ability as a reflective practice plays a pivotal role in shaping learners' motivation and self-efficacy in the teaching and learning processes which ultimately result in academic achievement. In L2 context, situating critical thinking within the framework of self-regulation, Ghanizadeh (2011) indicated that critical thinking ability has a facilitative role in enhancing self-regulation over time. Furthermore, Ghanizadeh and Moafian's study substantiated a dynamic interplay between CT and emotional intelligence (forthc). Thus, it can be plausibly concluded that the enhancement of learners' critical thinking through concept mapping tends to better equip them with other related affective, cognitive and meta-cognitive skills and abilities, conducive to effective learning.

The major implication of the present study for EFL instructors is to integrate the concept map strategy in their classes on a regular basis as a brainstorming tool or post- reading strategy. In so doing, teachers are in a better position to not only enhance learners' critical thinking ability but also monitor their weaknesses in reasoning and alternatively scaffold appropriate types of learning and thinking activities. To implement concept mapping as a post-reading strategy, teachers can encourage learners to concentrate on the main ideas or concepts residing in the text and put them in boxes. They should be then instructed to extract the possible relationships among ideas and connect the boxes with arrows. To better familiarize them with the concept map construction, teachers may create the concept map of the corresponding passage with some boxed and arrows unlabelled and ask the students to fill in 
the empty spaces of the incomplete teacher-constructed concept map. Subsequently, they must be encouraged to organize post-reading activities such as discussion, doing exercises, and reflective practices based on constructed maps.

The findings of the current study, however, must be treated with caution. The major limitation of this study lies in the fact that gender and age may not be accurately represented because the majority of the participants were in their twenties and predominantly female. So, it is recommended this study be replicated with larger sample size and sufficient numbers of participants from each sex and wider range of age. In this study learners' critical ability was assessed via tests. Subsequent studies may utilize both qualitative and quantitative research methods in order to investigate critical ability development in terms of both product and process. Furthermore, identical studies may investigate whether the concept mapping strategy would have positive impacts on learners' critical thinking in other areas such as writing and listening skills.

\section{References}

Acklam, R., \& Burgess, S. (2001). Advanced gold. Longman: Pearson education.

Brookfield, S. (1987). Developing Critical Thinking. Milton Keynes, SRHE and Open University Press.

Cañas, A. J. (2003). A Summary of Literature Pertaining to the Use of Concept Mapping Techniques and Technologies for Education and Performance Support. The Institute for Human and Machine Cognition.

Cañas, A. J., Hill, G., Carff, R., \& Suri, N. (2003). CmapTools: A knowledge modeling and sharing toolkit. Technical Report IHMC CmapTools, 93, 1. Institute for Human and Machine Cognition.

Carrell, P. L., Pharis, B. G., \& Liberto. J. C. (1989). Metacognitive strategy training for ESL reading. TESOL Quarterly, 23(4), 647-76. http://dx.doi.org/10.2307/3587536

Chularut, P., \& DeBacker, T.K. (2004). The influence of concept mapping on achievement, self-regulation, and self-efficacy in students of English as a second language. Contemporary Educational Psychology, 29, 248-263. http://dx.doi.org/10.1016/j.cedpsych.2003.09.001.

Dantas-Whitney, M. (2002). Critical reflection in the second language classroom through audiotaped journals. System, 30 (4), 543-555. http://dx.doi.org/10.1016/S0346-251X(02)00046-5.

Davidson, B., \& Dunham, R. (1997). Assessing EFL student progress in critical thinking with the Ennis-Weir Critical Thinking Essay Test. JALT Journal, 19(1), 43-57

Dewey, J. (1933). How we think: A restatement of the relation of reflective thinking tothe educational process. Lexington, MA: D.C. Heath.

Educational Testing Serve (2004). TOEFL actual tests administered in the past by ETS: 7 full-length paper-based exams for 2002-2004. Tehran: Ebteda publication.

Facione, N., \& Facione, P. (1996). Externalizing the critical thinking in knowledge development and critical judgment. Nursing Outlook, 44(3), 129-136. http://dx.doi.org/10.1016/S0029-6554(06)80005-9

Faravani, A. (2006). Investigating the effect of reading portfolios on the Iranian students' critical thinking ability, reading comprehension ability, and reading achievement. Unpublished MA thesis. Ferdowsi University of Mashhad, Iran.

Ghanizadeh, A. (2007a). On the impact of concept mapping on EFL learners' reading comprehension. Paper presented at the forth conference on issues in language teaching in Iran. Tehran University.

Ghanizadeh, A. (2007b). On validation of concept mapping as an assessment tool of L2 reading comprehension: A triangulation approach. Unpublished master's thesis. Ferdowsi University. Mashhad, Iran.

Ghanizadeh, A. (2011). An investigation into the relationship between self-regulation and critical thinking among Iranian EFL teachers. The Journal of Technology of Education, 5(3), 213-221

Ghanizadeh, A., \& Moafian, M. (forthc.). Critical thinking and emotional intelligence: investigating possible relationship among EFL learners and the contribution of age and gender. Submitted for publication.

Ivie, S. D. (2001). Metaphor: a model for teaching critical thinking. Contemporary Education, 72 (1), 18-23

Jonassen, D. H., Carr, C., \& Yueh, H. (1998). Computers as mindtools for engaging learners in critical thinking. Tech Trend, 43(2), 24-30. http://dx.doi.org/10.1007/BF02818172.

Kealey, B. T., Holland, J., \& Watson. M. (2005). Preliminary evidence on the association between critical thinking and performance in principles of accounting. Issues in Accounting Education, 20(1), 33-49. 
http://dx.doi.org/10.2308/iace.2005.20.1.33.

Liaw, M. L. (2007). Content-based reading and writing for critical thinking skills in an EFL context. English Teaching \& Learning, 31(2), 45-87

MacBride, R., \& Bonnette, R. (1995). Teacher and at-risk students' cognitions during open-ended activities: Structuring the learning environment for critical thinking. Teaching and Teacher Education, 11(4), 373-388

Meyers, C. (1986). Teaching Students to Think Critically. San Francisco: Jossey-Bass.

Mintzes, J. J., Wandersee, J. H., \& Novak, J. D. (1997). Meaningful learning in science: The human constructivist perspective. In G.D. Phye (Ed.), Handbook of academic learning: Construction of Knowledge. San Diego: Academic Press. pp. 405-447. http://dx.doi.org/10.1016/B978-012554255-5/50014-4

Novak, J. D. (1998). Learning, creating, and using knowledge: Concept maps as facilitative tools in schools and corporations. Mahweh, NJ: Lawrence Erlbaum Association.

Novak, J., \& Gowin, B. D. (1984). Learning how to learn. New York: Cambridge University Press.

Oliver, H., \& Utermohlen, R. (1995). An innovative teaching strategy: Using critical thinking to give learners a guide to the future. [Online] Available: www.siencedirect.com. (May 10, 2008)

Paul, R. (1988). Critical thinking in the classroom. Teaching $K-8,18$, 49-51

Pennycook, A. (1994). The cultural politics of English as an international language. London: Longman.

Phan, H. P. (2010). Critical thinking as a self-regulatory process component in teaching and learning. Psicothema, 22, 2, 284-292

Renner, C. E. (1996). Enrich learners' language production through content-based instruction. Paper presented at a National Conference on Lingua e Nuova Didattica, Modena, Italy. (ERIC Document Reproduction Service No. ED $411694)$

Scriven, M., \& Paul, R. (2004). Defining Critical Thinking. [Online] Available: http://www.criticalthinking.org/aboutCT/definingCT.shtml (September 22, 2008)

Spivey, N. N., \& Mellon, C. (1989). Constructing constructivism: Reading research in the United States. Occasional Paper, 12

Talebinezhad, M. R., \& Negari, G.M. (2007). The effect of explicit teaching of concept mapping in expository writing on EFL students' self-regulation. The Linguistics Journal, 2(1), 69-90

Thompson, C. (2002). Teaching critical thinking in EAP courses in Australia. TESOL Journal, 11(4), 15-20

Watson, G. B., \& Glaser, E. M. (2002). Watson-Glaser Critical Thinking Appraisal UK. London: The Psychological Corporation.

Wheeler, L. A., \& Collins, S.K.R. (2003). The influence of concept mapping on critical thinking in baccalaureate $\begin{array}{lllll}\text { nursing students. Journal of professional nursing, } & 19(6), & 339-346 .\end{array}$ http://dx.doi.org/10.1016/S8755-7223(03)00134-0

Wright, I. (2002). Is that right? Critical thinking and the social world of the young learner. Toronto: Pippin Publishing.

Yeh, Y. C. (2004). Nurturing reflective teaching during critical-thinking instruction in computer simulation program. Computers and Education, 42(2), 181-194. http://dx.doi.org/10.1016/S0360-1315(03)00071-X. 
Table 1. The subtests of CTA along with the corresponding descriptions

\begin{tabular}{|l|l|c|}
\hline Subtest & Description & Items \\
\hline Test 1. Inference & $\begin{array}{l}\text { Discriminating among degrees of truth or falsity of inference } \\
\text { drawn from given data. }\end{array}$ & $1-16$ \\
\hline $\begin{array}{l}\text { Test 2. Recognizing } \\
\text { Unstated Assumptions }\end{array}$ & $\begin{array}{l}\text { Recognizing unstated assumptions or presuppositions in given } \\
\text { statements or assertions. }\end{array}$ & $17-32$ \\
\hline Test 3. Deduction & $\begin{array}{l}\text { Determining whether certain conclusions necessarily follow } \\
\text { from information in given statement or premises. }\end{array}$ & $33-48$ \\
\hline Test 4. Interpretation & $\begin{array}{l}\text { Weighing evidence and deciding if generalizations or } \\
\text { conclusions based on the given data are warranted. }\end{array}$ & $49-64$ \\
\hline $\begin{array}{l}\text { Test 5. Evaluation of } \\
\text { Arguments }\end{array}$ & $\begin{array}{l}\text { Evaluation of Arguments: Distinguishing between arguments } \\
\text { that are strong and relevant and those that are weak or relevant to } \\
\text { a particular question at issue. }\end{array}$ & $65-80$ \\
\hline
\end{tabular}

Table 2. Independent T-Test displaying the results of pretest on proficiency level

\begin{tabular}{|l|c|c|c|c|c|}
\hline \multirow{2}{*}{} & \multicolumn{5}{|c|}{ t-test for Equality of Means } \\
\cline { 2 - 6 } & $\mathbf{t}$ & $\mathbf{d f}$ & Sig. (2-tailed) & Mean Difference & $\begin{array}{c}\text { Std. Error } \\
\text { Difference }\end{array}$ \\
\hline $\begin{array}{l}\text { Proficiency } \\
\text { test }\end{array}$ & 1.533 & 34 & .134 & 19.8 & 12.96991 \\
\hline
\end{tabular}

Table 3. Descriptive statistics of pretest on CTA

\begin{tabular}{|l|c|c|c|c|c|}
\hline CTA Scores & $\mathbf{N}$ & Minimum & Maximum & Mean & Std. Deviation \\
\hline Experimental & 18 & 31 & 62 & 45.5 & 10.17 \\
Control & 18 & 34 & 55 & 43.7 & 5.9 \\
\hline
\end{tabular}

Table 4. Independent T-Test displaying the results of pretest on CTA

\begin{tabular}{|l|c|c|c|c|c|}
\hline \multirow{2}{*}{} & \multicolumn{5}{|c|}{ t-test for Equality of Means } \\
\cline { 2 - 6 } & $\mathbf{t}$ & $\mathbf{d f}$ & Sig. (2-tailed) & Mean Difference & $\begin{array}{c}\text { Std. Error } \\
\text { Difference }\end{array}$ \\
\hline CTA & .560 & 34 & .579 & 1.555 & 2.777 \\
\hline
\end{tabular}


Table 5. Descriptive statistics of post-test on CTA

\begin{tabular}{|l|c|c|c|c|c|}
\hline CTA Scores & N & Minimum & Maximum & Mean & $\begin{array}{l}\text { Std. } \\
\text { Deviation }\end{array}$ \\
\hline Experimental & 18 & 45 & 68 & 54.88 & 10.22 \\
Control & 18 & 33 & 57 & 45.11 & 5.80 \\
\hline
\end{tabular}

Table 6. Independent T-Test displaying the results of post-test on CTA

\begin{tabular}{|l|c|c|c|c|c|}
\hline \multirow{2}{*}{} & \multicolumn{5}{|c|}{ t-test for Equality of Means } \\
\cline { 2 - 6 } & $\mathbf{t}$ & $\mathbf{d f}$ & Sig. (2-tailed) & Mean Difference & $\begin{array}{c}\text { Std. Error } \\
\text { Difference }\end{array}$ \\
\hline CTA & 3.527 & 34 & .001 & 9.777 & 2.77 \\
\hline
\end{tabular}

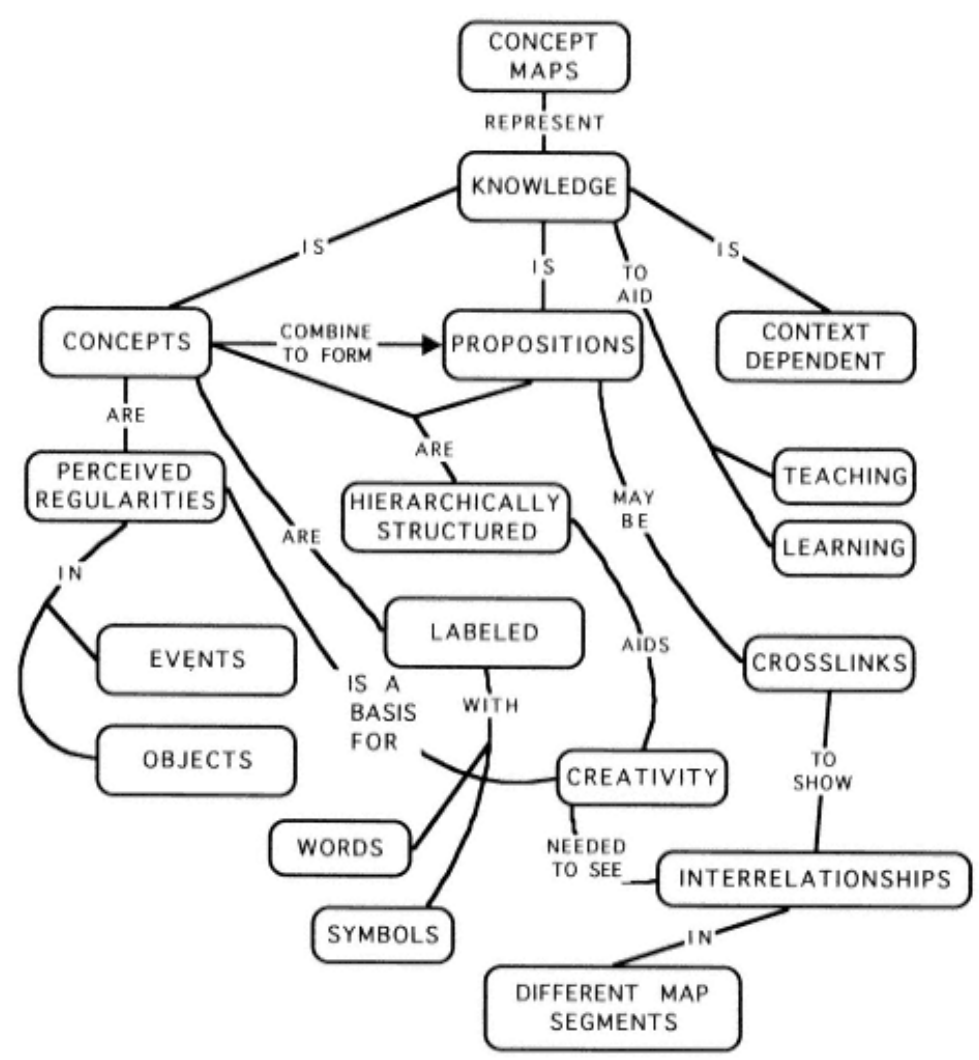

Figure 1. A concept map depicting key ideas and principles in constructing a good concept map (Adapted from Novak. 1998. p. 32) 


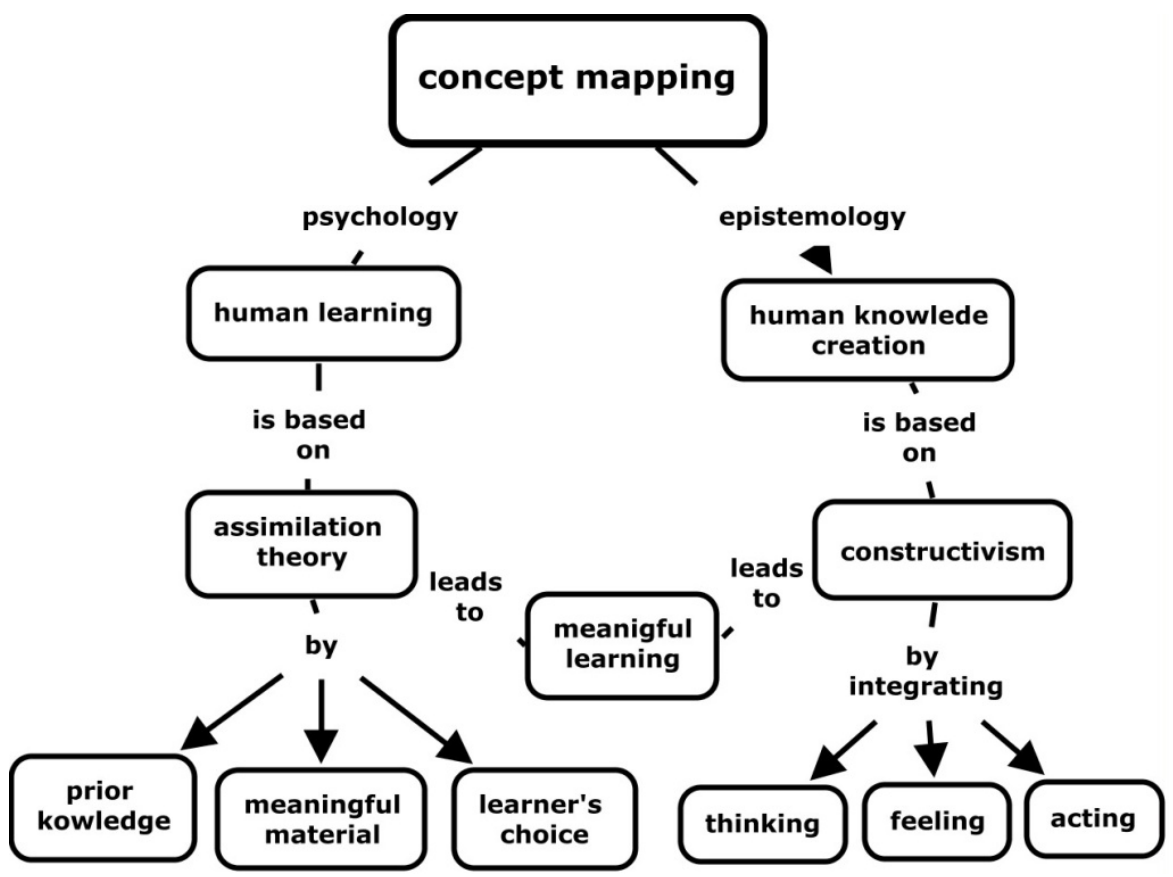

Figure 2. A concept map illustrating the underlying process and nature of meaningful learning in human learning and knowledge construction.

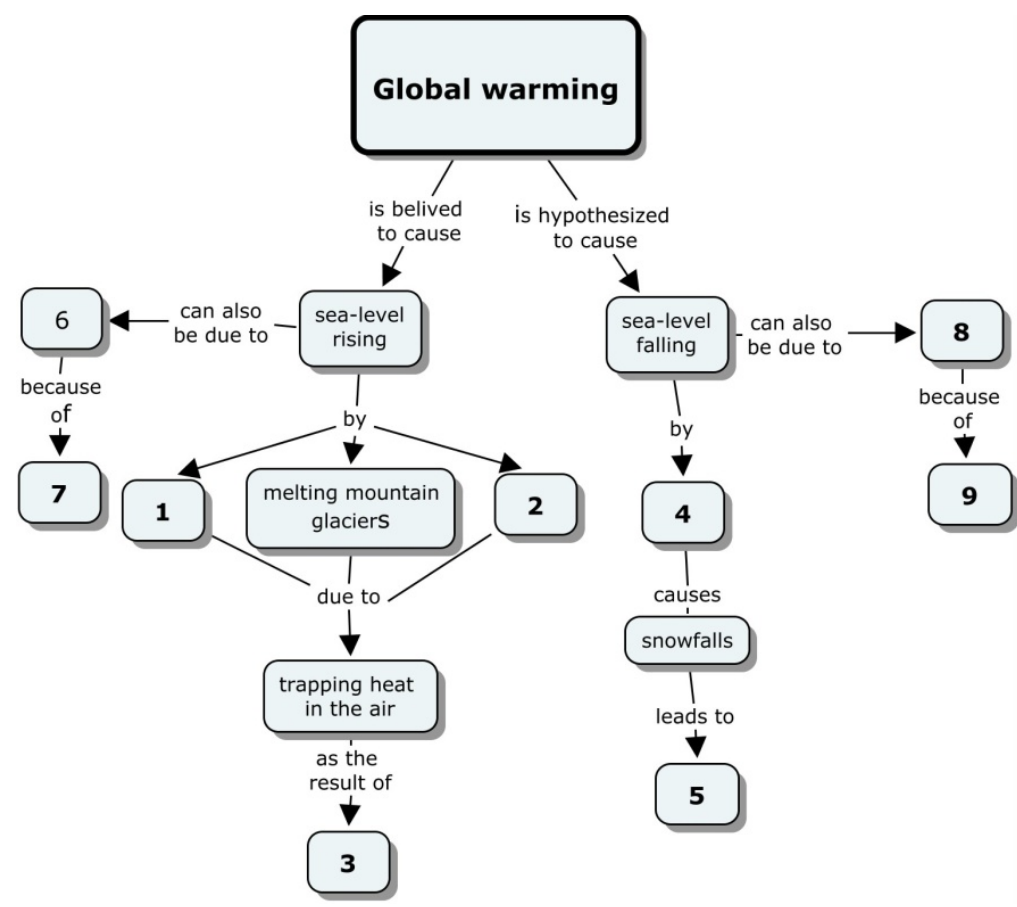

Figure 3. A teacher made concept map of IELTS (2003) reading passage, requiring the learners to fill in the numbered squares.

Instruction: when completing the concept map, start from the central idea "Global warming", then proceed in the order of the numbered squares from 1-9. 


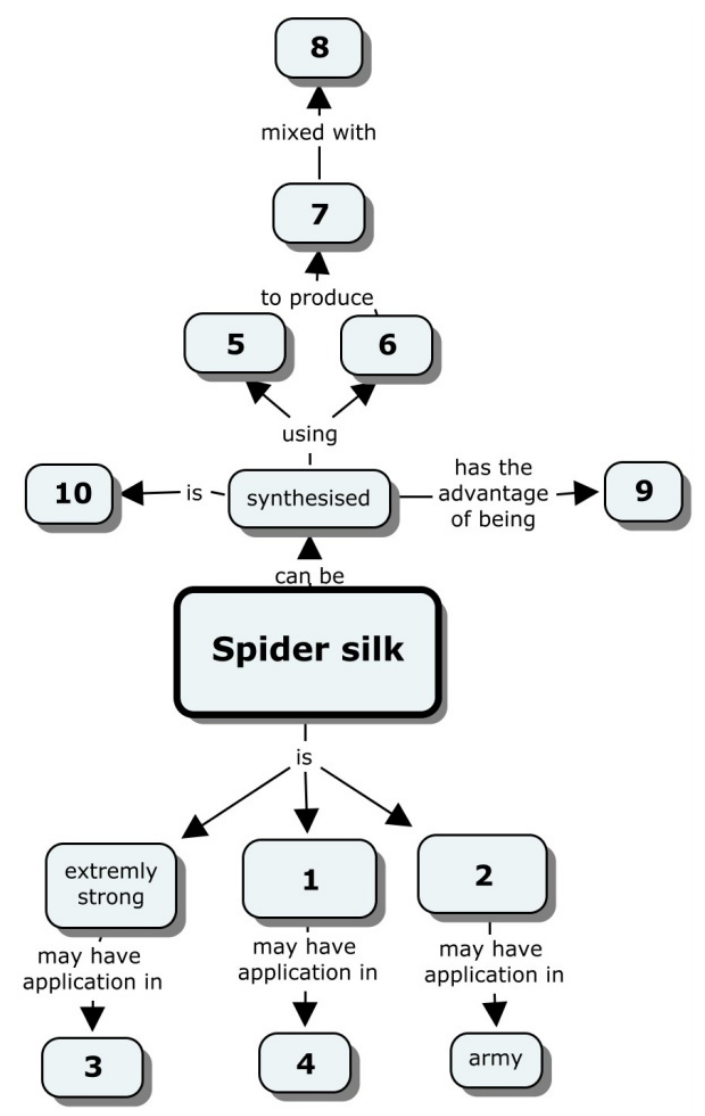

Figure 4. A teacher made concept map of IELTS (2003) reading passage, requiring the learners to fill in the numbered squares.

Instruction: when completing the concept map, start from the central idea "spider silk", then proceed in the order of the numbered squares from $1-10$. 